\title{
Vitamin D Insufficiency Exacerbates Adipose Tissue Macrophage Infiltration and Decreases AMPK/SIRT1 Activity in Obese Rats
}

\author{
Eugene Chang and Yangha Kim * \\ Department of Nutritional Science and Food Management, Ewha Womans University, Seoul 03760, Korea; \\ eugenics77@hotmail.com \\ * Correspondence: yhmoon@ewha.ac.kr; Tel.: +82-2-3277-3101
}

Received: 7 February 2017; Accepted: 27 March 2017; Published: 29 March 2017

\begin{abstract}
Obesity is recognized as a state of chronic low-grade systemic inflammation due to adipose tissue macrophage infiltration and production of proinflammatory adipokines. Decreased vitamin $\mathrm{D}$ status is associated with obesity. The specific aim of the present study is to investigate the effects of vitamin D on obesity-induced adipose tissue inflammation. Male Sprague-Dawley rats were randomized and fed a normal diet (NOR, $1000 \mathrm{IU}$ vitamin $\mathrm{D} / \mathrm{kg}$ diet), a $45 \%$ high-fat diet (HF, $1000 \mathrm{IU}$ vitamin $\mathrm{D} / \mathrm{kg}$ diet), or a $45 \%$ high-fat diet containing $25 \mathrm{IU}$ vitamin $\mathrm{D} / \mathrm{kg} \operatorname{diet}(\mathrm{HF}+\mathrm{LVD}$ ) for 12 weeks. The vitamin D-insufficient diet (HF+LVD) led to vitamin D inadequacy as determined by serum 25(OH)D level, $68.56 \pm 7.97 \mathrm{nmol} / \mathrm{L}$. The HF+LVD group exacerbated HF-increased adipocyte size, adipogenic gene expression of $\operatorname{PPAR} \gamma$, adipose tissue macrophage recruitment, and proinflammatory cytokine IL- 6 and TNF $\alpha$ levels in epididymal white adipose tissue. In addition, vitamin D insufficiency significantly decreased mRNA levels of $\beta$-oxidation-related genes such as CPT1 $\alpha$, PGC1 $\alpha$, PPAR $\alpha$, VLCAD, LCAD, MCAD, and UCP1. Moreover, significant decrements of SIRT1 and AMPK activity were noted in obese rats fed with a vitamin D-insufficient diet. The observed deleterious effects of vitamin $\mathrm{D}$ insufficiency on adipose tissue expansion, immune cell infiltration and inflammatory status suggest vitamin D plays a beneficial role in adipocyte metabolic metabolism and obesity progression. SIRT1 and AMPK activity may play a role in the mechanism of vitamin D action.
\end{abstract}

Keywords: adenosine monophosphate-activated protein kinase (AMPK); adipose tissue macrophage infiltration; obesity; sirtulin 1 (SIRT1); vitamin D

\section{Introduction}

Obesity is characterized by excessive fat accumulation in adipose tissue [1,2]. Increased adipose tissue mass is associated with changes in the endocrine and metabolic functions of adipose tissue, reflecting the increased number of infiltrated immune cells [3-5] and the production and secretion of biologically active proteins, including leptin, tumor necrosis factor $\alpha$ (TNF $\alpha$ ), interleukin-6 (IL-6), monocyte chemoattractant protein-1 (MCP-1), resistin and adiponectin [6,7]. Increased adiposity and local inflammation in adipose tissue are linked to alterations in systemic physiology and the pathogenesis of obesity-induced complications [8-10]. Thus, an understanding of the molecular mechanisms of adipose tissue formation, function and changes during the progression of obesity is required for the prevention and treatment of obesity and obesity-related complications.

There is a strong association between vitamin D status and obesity, as low vitamin D status is highly prevalent in obese people [11,12]. Negative relationships between body fat content and 25-hydroxyvitamin D $(25(\mathrm{OH}) \mathrm{D})$, the most accepted marker of vitamin D status, have been reported [13-16]. In parallel with body fat mass, the synthesis and release of proinflammatory 
adipocyte-derived proteins are also affected by vitamin D status. Vitamin D deficiency, also known as hypovitaminosis D, is positively associated with serum levels of inflammatory markers, such as IL-6, $\mathrm{TNF} \alpha$ and C-reactive protein in obese participants $[17,18]$. In this respect, the influence of vitamin D on inflammation has been investigated using in vitro adipocytes. In some in vitro studies, vitamin $\mathrm{D}$ shows proinflammatory properties $[19,20]$, whereas anti-inflammatory pathways are activated with similar vitamin D concentrations in adipocytes [21-24]. Recently published studies show that gene modification of the vitamin $\mathrm{D}$ receptor (VDR) regulates fatty acid oxidation, energy metabolism and browning of white adipose tissue in part through UCP1 expression $[25,26]$, demonstrating regulation of vitamin D in obesity. In addition, 1,25-dihydroxyvitamin D3 treatment suppresses brown adipocyte differentiation and mitochondrial respiration [27]. Because of discrepancies between the observed effects of vitamin $\mathrm{D}$ on inflammation and the role of vitamin $\mathrm{D}$ in regulating brown adipose tissue development and function, the mechanisms by which vitamin D influences adipocyte tissue formation, adipokine production and secretion and adipose tissue inflammation during the development of obesity need to be elucidated by further investigation.

Adenosine monophosphate-activated protein kinase (AMPK) and sirtuin 1 (SIRT1), a nicotinamide adenine dinucleotide (NAD)-dependent protein deacetylase, have emerged as critical energy sensors and inflammatory regulators. In the visceral adipose tissue of obese humans, reduced AMPK activity is closely associated with adipose tissue inflammation [28]. Studies in genetically obese and high-fat-diet-fed rodents demonstrate that body fat deposition is influenced by AMPK activation [29-31]. AMPK enhances SIRT1 by increasing NAD/NADH ratio and decreases adipose tissue macrophage infiltration and inflammation [32-34]. In addition, AMPK and SIRT1 act as regulators of fatty acid oxidation and mitochondrial biogenesis by phosphorylation and deacetylation of peroxisome proliferative activated receptor gamma coactivator $1 \alpha$ (PGC1 $\alpha)$ [35]. SIRT1 protects diet-induced obesity and inflammation and obesity-associated metabolic dysfunction [36-39]. In addition, vitamin D decreases adipocyte fat accumulation and increases SIRT1 activation in adipocytes [40]. Thus, AMPK and SIRT1 activation have been proposed as key regulators to prevent obesity and obesity-related metabolic dysfunction. In the present study, we investigate the effects of vitamin $\mathrm{D}$ on fat accumulation, adipose tissue macrophage infiltration, proinflammatory cytokines and AMPK/SIRT1 activity in diet-induced obese rats.

\section{Materials and Methods}

\subsection{Animals and Diets}

Animal housing and procedures were approved by the Ethics Committee for Animal Experiments of the Ewha Womans University in Seoul, South Korea (permission number: 2015-15-064). Three-week-old male Sprague-Dawley rats $(n=23)$ were obtained from Doo Yeol Biotech (Seoul, Korea), housed individually in wire-mesh-bottomed polypropylene cages and maintained in a UVB light-free environment on a 12-h light/dark cycle at constant room temperature $\left(22 \pm 2{ }^{\circ} \mathrm{C}\right)$ and humidity $(55 \% \pm 5 \%)$. After 1 week of acclimation with laboratory chow, the rats were randomly divided into three diet groups ( $n=7-9$ /group, Table 1): (1) normal diet (NOR, $10 \%$ fat diet with $1000 \mathrm{IU}$ vitamin D/kg diet); (2) high-fat diet (HF, 45\% fat diet with $1000 \mathrm{IU}$ vitamin D/kg diet); or (3) $45 \%$ fat diet containing $25 \mathrm{IU}$ vitamin $\mathrm{D} / \mathrm{kg}$ diet (HF+LVD). In the present study, dietary vitamin D levels were chosen to achieve target $25(\mathrm{OH}) \mathrm{D}$ status levels of inadequacy and adequacy without adverse effects [41-43]. All diets were prepared by Research Diets, Inc. (New Brunswick, NJ, USA). Body weight and food intake were monitored twice a week. All rats and food were weighed every Monday and Thursday between 09:00 and 11:30. Food was weighed before it was given to each rat in each cage. To measure food intake, both split food and remaining uneaten food were weighed and subtracted from weighed food before being provided to the animals. At the end of the 12-week animal experiment, the rats were fasted overnight and killed by $\mathrm{CO}_{2}$ narcosis. After blood collection by cardiac puncture, the samples were centrifuged at $1500 \times g$ for $20 \mathrm{~min}$ at $4{ }^{\circ} \mathrm{C}$ to obtain serum and stored at $-20{ }^{\circ} \mathrm{C}$ until 
analysis. Serum measurements of $25(\mathrm{OH}) \mathrm{D}$, metabolic parameters, cytokines and SIRT1 activity were conducted. Tissues were dissected, weighed, frozen in liquid nitrogen and stored at $-70^{\circ} \mathrm{C}$ for further analysis, or were fixed, embedded in paraffin and sectioned for histologic analysis.

Table 1. Content of intervention diets.

\begin{tabular}{cccc}
\hline & NOR & HF & HF+LVD \\
\hline Casein $(\mathrm{g})$ & 200 & 200 & 200 \\
L-Cystine $(\mathrm{g})$ & 3 & 3 & 3 \\
Corn starch $(\mathrm{g})$ & 550 & 72.8 & 72.8 \\
Maltodextrin $(\mathrm{g})$ & 150 & 100 & 100 \\
Sucrose $(\mathrm{g})$ & 0 & 172.8 & 172.8 \\
Cellulose $(\mathrm{g})$ & 50 & 50 & 50 \\
Soybean oil (g) & 25 & 25 & 25 \\
Lard (g) & 20 & 177.5 & 177.5 \\
Total kcal & 4057 & 4057 & 4057 \\
Carbohydrate (\% of energy) & 70 & 35 & 35 \\
Fat (\% of energy) & 10 & 45 & 45 \\
Vitamin D (IU / kg diet) & 1000 & 1000 & 25 \\
\hline
\end{tabular}

NOR, $10 \%$ fat diet with 1000 IU vitamin D; HF, 45\% fat diet with 1000 IU vitamin D; HF+LVD, high-fat plus low vitamin $\mathrm{D}, 45 \%$ fat diet containing $25 \mathrm{IU}$ vitamin $\mathrm{D}$.

\subsection{Measurements of Serum Metabolic Parameters}

Serum concentrations of alanine transaminase (ALT), aspartate transaminase (AST), glucose, total cholesterol (TC), triglycerides (TG), high-density lipoprotein (HDL) cholesterol and low-density lipoprotein (LDL) cholesterol were measured using an automatic enzymatic procedure (Roche Diagnostics, Mannheim, Germany) and a Hitachi 7600 autoanalyzer (Tokyo, Japan), according to the manufacturers' recommended protocols. Body vitamin D status was evaluated using a rat $25(\mathrm{OH}) \mathrm{D}$ enzyme-linked immunosorbent assay (ELISA) kit (ALPCO, Salem, NH, USA). In the first step, 25(OH)D was bound to a specific monoclonal antibody. A fixed amount of biotinylated $25(\mathrm{OH}) \mathrm{D}$ was conjugated with tetramethylbenzidine (TMB) chromogenic substrate at room temperature in the presence of horseradish peroxidase (HRP). Exposure to direct sunlight was avoided. The amount of substrate turnover was determined calorimetrically by measuring the absorbance at $450 \mathrm{~nm}$, which is inversely proportional to the total $25(\mathrm{OH}) \mathrm{D}(\mathrm{D} 2$ and D3) concentration. Measurement of serum insulin was carried out using a radioimmunoassay (RIA) method with a rat insulin RIA kit (Linco Research, Inc., St. Charles, MO, USA). ${ }^{125}$ I-labeled insulin and a rat insulin antiserum were utilized to determine the level of rat insulin in serum separated with appropriate dosages of anticoagulant by the double antibody/PEG technique.

\subsection{Histological Analysis of Adipose Tissue and Cell Size Determination}

Epididymal adipose tissue (EAT) was harvested, fixed in $4 \%$ formaldehyde overnight, embedded in paraffin, sectioned and stained with hematoxylin and eosin (H\&E). Digital images were acquired with a microscope (Olympus, Tokyo, Japan). The size of the adipocyte area was determined using Image J software (National Institutes of Health, Bethesda, MD, USA).

\subsection{Immunohistochemistry and Crown-Like Structure (CLS) Quantification}

Histological sections of adipose tissue were dewaxed in xylenes, rehydrated and stained using monoclonal anti-mouse F4/80 antibody (Serotec, Raleigh, NC, USA). A Polink-2 Plus HRP Anti-rat DAB Detection kit was used (Golden Bridge International, Inc., Mukilteo, WA, USA) according to the manufacturer's instructions. Subsequently, the reaction products were visualized using diaminobenzidine (Golden Bridge International, Inc.) and counterstained with Mayer hematoxylin (ScyTek, Logan, UT, USA). Adipocyte death was quantified by the number of crown-like structures 
(CLS) within histologic sections of epididymal adipose tissue in which F4/80-positive macrophages surround a single adipocyte.

\subsection{RNA Isolation, Reverse Transcription and Real-Time Quantitative Polymerase Chain Reaction (RT-PCR)}

Isolation of RNA from epididymal adipose tissue was performed using an RNeasy Lipid Tissue Mini Kit (QIAGEN, Valencia, CA, USA) according to the manufacturer's protocol. cDNA was synthesized from $1 \mu \mathrm{g}$ of total RNA using a MMLV Reverse Transcriptase Kit (Bioneer, Daejeon, Korea). The reaction was performed at $37^{\circ} \mathrm{C}$ for $60 \mathrm{~min}$ followed by incubation at $95{ }^{\circ} \mathrm{C}$ for $5 \mathrm{~min}$. Primers used are shown in Table 2. The polymerase chain reaction (PCR) parameters were as follows: pre-denaturation at $95^{\circ} \mathrm{C}$ for $10 \mathrm{~min}$, followed by 50 cycles of denaturation at $95^{\circ} \mathrm{C}$ for $15 \mathrm{~s}$, annealing at $60{ }^{\circ} \mathrm{C}$ for $20 \mathrm{~s}$ and extension at $72{ }^{\circ} \mathrm{C}$ for $20 \mathrm{~s}$. Data were analyzed using the $\Delta \Delta \mathrm{Ct}$ method for relative quantification [44]. Expression of each target was normalized to the average of $\beta$-actin as a control and expressed as the fold change related to the NOR group.

Table 2. Primers used for Real-Time Quantitative Polymerase Chain Reaction (RT-PCR).

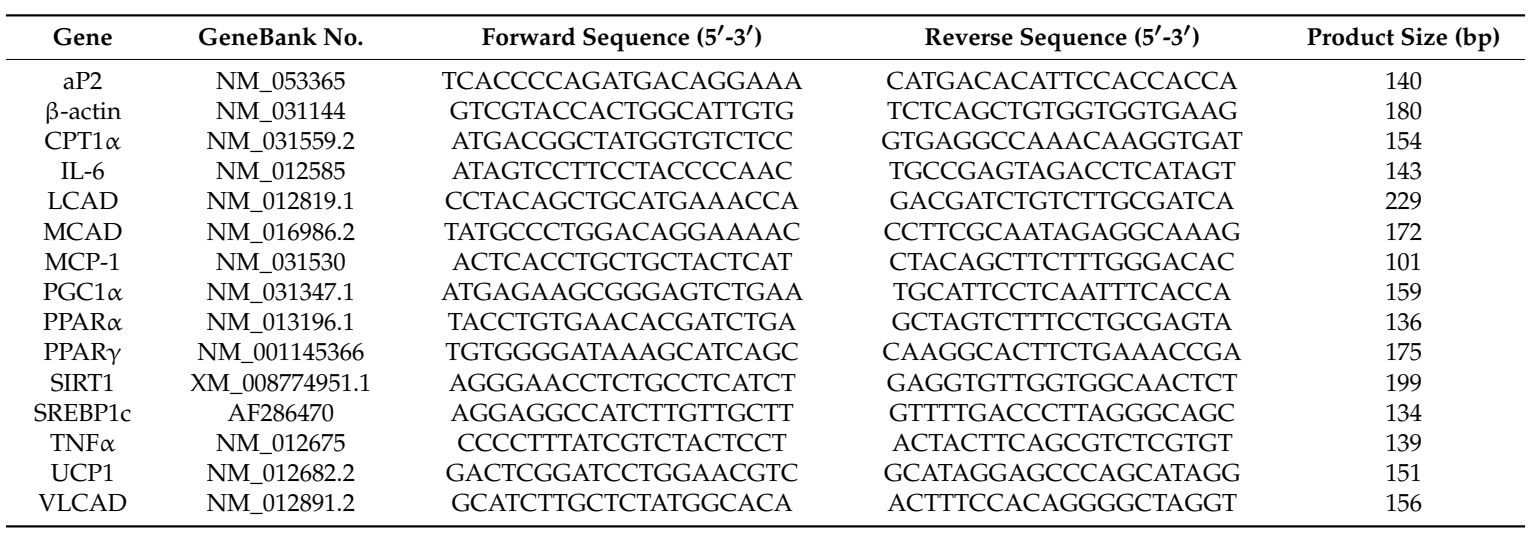

aP2, fatty acid-binding protein 2; CPT1 $\alpha$, carnitine palmitoyltransferase $1 \alpha$; IL-6, interleukin-6; LCAD, long-chain acyl-CoA dehydrogenase (Acadl); MCAD, medium-chain acyl-CoA dehydrogenase (Acadm); MCP-1, monocyte chemoattractant protein-1; PGC1 $\alpha$, peroxisome proliferative activated receptor gamma coactivator $1 \alpha$; PPAR $\alpha$, peroxisome proliferator-activated receptor $\alpha$; PPAR $\gamma$, peroxisome proliferator-activated receptor $\gamma$; SIRT1, sirtuin 1; SREBP1c, sterol regulatory element-binding protein $1 \mathrm{c} ; \mathrm{TNF} \alpha$, tumor necrosis factor $\alpha$; UCP1, uncoupling protein 1; VLCAD, very long-chain acyl-CoA dehydrogenase (Acadvl).

\subsection{Cytokine Assay}

Concentrations of IL- 6 and TNF $\alpha$ in serum and adipose tissue were measured using Quantikine ELISA kits (R\&D systems, Minneapolis, MN, USA) according to the manufacturer's protocols. Quantitative sandwich enzyme immunoassay technique utilized specific monoclonoal antibodies for rat IL-6 and TNF $\alpha$ under light protection. Color intensity in proportion to the amount of IL- 6 and TNF $\alpha$ was measured at $450 \mathrm{~nm}$. Epididymal adipose tissue was homogenized in radioimmunoprecipitation assay (RIPA) buffer (Sigma-Aldrich, St. Louis, MO, USA) with 1\% protease inhibitor cocktails (Roche, Mannheim, Germany). Cytokine levels in adipose tissue were normalized to their respective protein concentrations and expressed as $\mathrm{ng} / \mathrm{mg}$ protein.

\subsection{SIRT1 Activity Assay}

SIRT1 activity was measured using an SIRT1 activity assay kit (Abcam, Cambridge, MA, USA). After extracting the nuclear fraction, fluorescence intensity was detected at $340 \mathrm{~nm}$ excitation and $460 \mathrm{~nm}$ emission using a microplate fluorescence reader (Varioskan Flash, Thermo Scientific, Waltham, MA, USA). Protein was determined using a BCA protein assay kit (Thermo Scientific). SIRT1 activity was normalized to their respective protein concentrations and expressed as the fold change compared to the NOR group. 


\subsection{AMPK Activity Assay}

AMPK activity was measured using an AMPK Kinase Assay kit (MBL International Co., Woburn, MA, USA). AMPK activity was semi-quantified using mouse IRS-1 serine 789, which can be phosphorylated by AMPK. Colorimetric reaction was developed by peroxidase conjugated anti-mouse IgG and TMB. The absorbance was measured at $450 \mathrm{~nm}$ using a microplate reader. AMPK activity was normalized to their respective protein concentrations and expressed as the fold change compared to the NOR group.

\subsection{Statistical Analysis}

Data are presented as the mean \pm standard error of the mean (SEM). Statistical differences between two and three groups were determined by Student's $t$-test or one-way analysis of variance (ANOVA) following Student-Newman-Keuls multiple comparisons method. Statistical significance was defined at $p<0.05$ using SPSS software (version 21; IBM Corporation, Armonk, NY, USA).

\section{Results}

\subsection{Dietary Vitamin D-Insufficient Diet Exacerbates High Fat Diet-Increased Body Weight Gain and Fat Deposition}

A total of 23 Sprague-Dawley rats were fed $10 \%$ fat or $45 \%$ fat diets containing 25 or $1000 \mathrm{IU}$ vitamin $\mathrm{D} / \mathrm{kg}$ diet for 12 weeks. There was no significant difference in initial body weight, energy efficiency, or weights of liver or skeletal muscle (Figure 1A, Table 3). The vitamin D-insufficient diet (HF+LVD) group showed a significant increase in body weight compared to the vitamin $\mathrm{D}$ adequate diet (HF) group, despite equal food efficiency and energy efficiency (Figure 1A, Table 3). The HF+LVD group displayed significant increase in adipose tissue weight (Figure 1C) and adipocyte size (Figure 1D,E) compared to the HF group. These results demonstrate that vitamin D insufficiency exacerbates diet-induced obesity and adipose tissue expansion.

Table 3. Effects of vitamin D on body weight, food intake and tissue weight.

\begin{tabular}{lccc}
\hline & NOR $(\boldsymbol{n}=\mathbf{9})$ & HF $(\boldsymbol{n}=\mathbf{7})$ & HF+LVD $(\boldsymbol{n}=\mathbf{7})$ \\
\hline Body weight (g) & & & \\
$\quad$ - Initial body weight & $105.86 \pm 2.64$ & $109.69 \pm 2.50$ & $110.75 \pm 3.36$ \\
$\quad$ - Final body weight & $483.84 \pm 11.49^{\mathrm{a}}$ & $532.21 \pm 10.36^{\mathrm{b}}$ & $571.08 \pm 7.52^{\mathrm{c}}$ \\
$\quad$ - Weight change & $377.98 \pm 11.63^{\mathrm{a}}$ & $422.53 \pm 10.65^{\mathrm{b}}$ & $458.03 \pm 8.91^{\mathrm{c}}$ \\
Food intake (g/day) & $20.66 \pm 0.37^{\mathrm{b}}$ & $18.03 \pm 0.43^{\mathrm{a}}$ & $20.03 \pm 0.37^{\mathrm{b}}$ \\
Energy intake (kcal/day) & $79.43 \pm 1.42^{\mathrm{a}}$ & $85.23 \pm 2.02^{\mathrm{b}}$ & $94.68 \pm 1.75^{\mathrm{c}}$ \\
Food efficiency (g gain/g consumed) & $0.22 \pm 0.005^{\mathrm{a}}$ & $0.28 \pm 0.004^{\mathrm{b}}$ & $0.28 \pm 0.004^{\mathrm{b}}$ \\
Energy efficiency (g gain/kcal consumed) & $0.057 \pm 0.002$ & $0.060 \pm 0.000$ & $0.059 \pm 0.001$ \\
Tissue weight (g/100 g body weight) & & & \\
$\quad$ - Liver & $2.87 \pm 0.06$ & $3.05 \pm 0.11$ & $3.14 \pm 0.11$ \\
$\quad$ - Skeletal muscle & $0.68 \pm 0.03$ & $0.61 \pm 0.04$ & $0.66 \pm 0.05$ \\
\hline
\end{tabular}

Data are expressed as the mean \pm SEM ( $n=7-9$ /group). Significant differences among groups are represented with different letters $(\mathrm{a}, \mathrm{b}, \mathrm{c})$ at $p<0.05$. NOR, $10 \%$ fat diet with $1000 \mathrm{IU}$ vitamin $\mathrm{D} ; \mathrm{HF}, 45 \%$ fat diet with $1000 \mathrm{IU}$ vitamin $\mathrm{D} ; \mathrm{HF}+\mathrm{LVD}$, high-fat plus low vitamin $\mathrm{D}, 45 \%$ fat diet containing $25 \mathrm{IU}$ vitamin $\mathrm{D}$. 
A

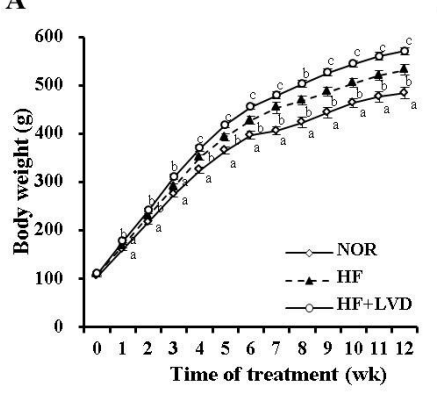

D

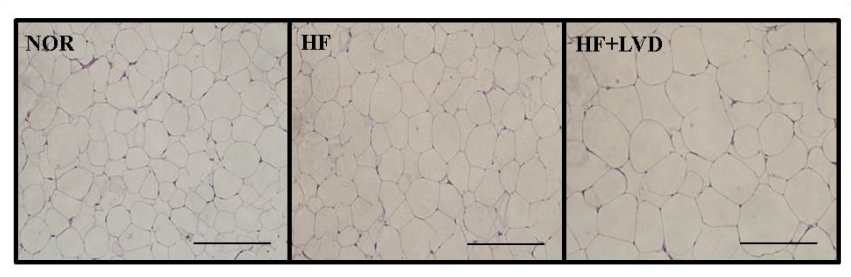

B

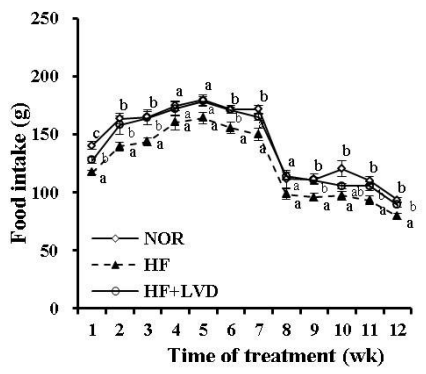

Time of treatment (wk)

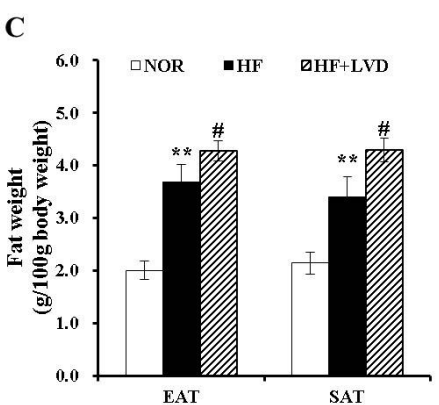

$\mathbf{E}$

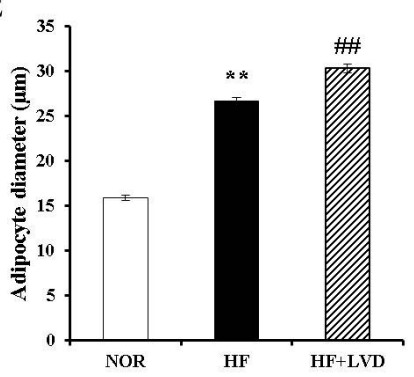

Figure 1. Effects of vitamin D-insufficient diet on body weight gain and fat weight in obese rats. Body weight gain (A), food intake (B) and weight of epididymal adipose tissue (EAT) and subcutaneous adipose tissue (SAT) (C). Representative hematoxylin and eosin stained EAT section (scale bar, $50 \mu \mathrm{m}$; magnification, $40 \times$ ) (D). Average adipocyte diameter of adipocytes within adipose tissue (E) and data is expressed as the mean \pm SEM. Bars with different letters $(a, b, c)$ show significant difference $(p<0.05) .{ }^{*} p<0.05$; ${ }^{* *} p<0.01$ compared to NOR. \# $p<0.05$; \#\# $p<0.01$ compared to HF. NOR, $10 \%$ fat diet with $1000 \mathrm{IU}$ vitamin D ( $n=9) ; \mathrm{HF}, 45 \%$ fat diet with $1000 \mathrm{IU}$ vitamin D $(n=7) ; \mathrm{HF}+\mathrm{LVD}, 45 \%$ fat diet containing $25 \mathrm{IU}$ vitamin $\mathrm{D}(n=7)$.

\subsection{Influence of a Vitamin D-Insufficient Diet on Serum Vitamin D and Metabolic Parameters}

Next, we investigated the effect of dietary vitamin D levels on blood 25(OH)D concentration, the best blood indicator of vitamin D status. Regardless of fat content in the diet, the NRC vitamin D level requirement, $1000 \mathrm{IU}$ vitamin $\mathrm{D} / \mathrm{kg}$ diet [41], led to a $25(\mathrm{OH}) \mathrm{D}$ concentration over $100 \mathrm{nmol} / \mathrm{L}$, which was proposed to be optimal. In contrast, serum 25(OH)D levels in 25 IU vitamin D/kg diet (HF+LVD) was less than $80 \mathrm{nmol} / \mathrm{L}$, defined as vitamin D inadequacy or insufficiency in humans $[45,46]$. This demonstrates that dietary vitamin D levels affect the systemic vitamin D status in the body.

During the progression of obesity, the influence of vitamin D insufficiency on changes in blood metabolic characteristics was determined using enzymatic assays using commercial kits. Among HF-increased serum levels of insulin, TG, TC, LDL-cholesterol, serum insulin, TC and LDL-cholesterol concentrations were exacerbated by vitamin D insufficiency. Serum levels of AST and ALT were not statistically different among the groups (Table 4).

\subsection{Influene of Vitamin D Insufficiency on Gene Expression invovled in Adipogensis and Fat Oxidation}

We evaluated whether vitamin D inadequacy exacerbates HF-induced body weight gain and fat deposition by gene expression related to adipogenesis or fatty acid oxidation in adipose tissue. mRNA levels of adipogenic genes, such as fatty acid-binding protein 2 (aP2), peroxisome proliferator activated receptor $\gamma$ (PPAR $\gamma$ ) and sterol regulatory element binding protein 1c (SREBP1c), were measured using RT-PCR. Adipogenic gene levels of aP2, PPAR $\gamma$ and SREBP1c were significantly increased by the HF diet $(p<0.05)$. The vitamin D-insufficient diet $(H F+L V D)$ led to a significant induction of only PPAR $\gamma$ gene expression, approximately 2.7-fold higher than that of the HF diet (Figure 2A). In contrast, mRNA levels involved in $\beta$-oxidation, such as carnitine palmitoyltransferase 
$1 \alpha(\mathrm{CPT} 1 \alpha), \mathrm{PGC} 1 \alpha, \mathrm{PPAR} \alpha$, very long-chain acyl-CoA dehydrogenase (VLCAD), long-chain acyl-CoA dehydrogenase (LCAD) and medium-chain acyl-CoA dehydrogenase (MCAD), as well as gene expression of uncoupling protein 1 (UCP1) related to thermogenesis and energy expenditure, were significantly suppressed by vitamin D inadequacy (Figure 2B).

Table 4. Metabolic serum characteristics of low-fat control (NOR) and high fat control (HF) and vitamin D-insufficient (HF+LVD)-fed rats.

\begin{tabular}{lccc}
\hline & NOR $(\boldsymbol{n}=\mathbf{9})$ & HF $(\boldsymbol{n}=\mathbf{7})$ & HF+LVD $(\boldsymbol{n}=\mathbf{7})$ \\
\hline 25(OH)D $(\mathrm{nmol} / \mathrm{L})$ & $102.59 \pm 6.75$ & $103.46 \pm 5.76$ & $68.56 \pm 7.97^{\#}$ \\
Glucose $(\mathrm{mmol} / \mathrm{L})$ & $12.28 \pm 0.98$ & $14.03 \pm 2.40$ & $16.74 \pm 1.95^{*}$ \\
Insulin $(\mu \mathrm{H} / \mathrm{mL})$ & $39.90 \pm 4.19$ & $58.77 \pm 5.06^{* *}$ & $75.56 \pm 8.17^{\#}$ \\
Lipids $(\mathrm{mmol} / \mathrm{L})$ & & & \\
- Triglyceride & $0.87 \pm 0.10$ & $1.22 \pm 0.08^{*}$ & $1.80 \pm 0.28^{*}$ \\
- Total cholesterol & $1.97 \pm 0.13$ & $2.63 \pm 0.13^{* *}$ & $3.56 \pm 0.54^{\#}$ \\
- HDL cholesterol & $2.13 \pm 0.10$ & $2.35 \pm 0.10$ & $2.35 \pm 0.21$ \\
- LDL cholesterol & $0.21 \pm 0.03$ & $0.29 \pm 0.03^{* *}$ & $0.39 \pm 0.03^{\# \#}$ \\
AST (IU /L) & $107.50 \pm 11.82$ & $107.00 \pm 13.85$ & $107.83 \pm 12.97$ \\
ALT (IU/L) & $33.63 \pm 6.45$ & $30.60 \pm 4.23$ & $30.71 \pm 2.56$ \\
\hline
\end{tabular}

Data are expressed as the mean \pm SEM $\left(n=7-9 /\right.$ group). ${ }^{*} p<0.05 ;{ }^{* *} p<0.01$ compared to NOR. $\# p<0.05 ; \# \#<0.01$ compared to HF. NOR, 10\% fat diet with 1000 IU vitamin D; HF, 45\% fat diet with $1000 \mathrm{IU}$ vitamin D; HF+LVD, high-fat plus low vitamin D, 45\% fat diet containing 25 IU vitamin D. 25(OH)D, 25-hydroxyvitamin D; HDL, high-density lipoprotein; LDL, low-density lipoprotein; AST, aspartate aminotransferase; ALT, alanine aminotransferase.

A. Adipogenesis

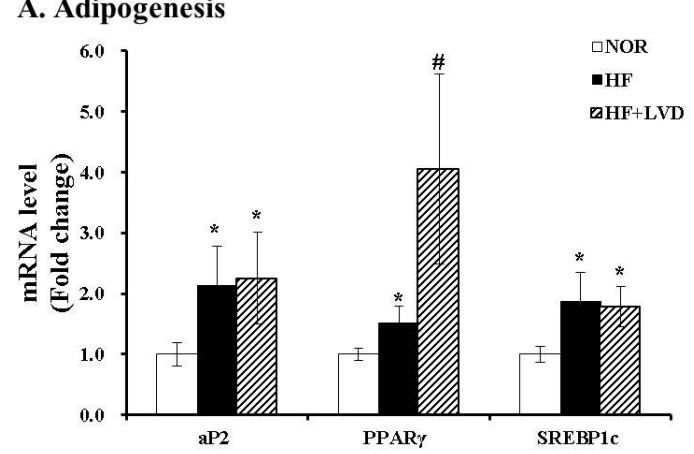

B. Fatty acid oxidation

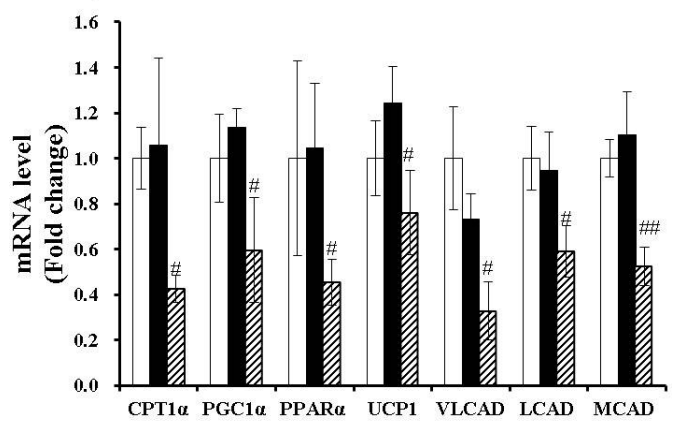

Figure 2. Influence of vitamin D insufficiency on gene expression involved in adipogenesis (A) and fatty acid oxidation (B). mRNA levels were determined by RT-PCR and normalized for all samples to $\beta$-actin. The results are expressed as the fold change compared to NOR. The value of each bar represents the mean \pm SEM. ${ }^{*} p<0.05 ;{ }^{* *} p<0.01$ compared to NOR. \# $p<0.05$; \#\# $p<0.01$ compared to HF. NOR, $10 \%$ fat diet with $1000 \mathrm{IU}$ vitamin $\mathrm{D}(n=9)$; HF, $45 \%$ fat diet with $1000 \mathrm{IU}$ vitamin $\mathrm{D}(n=7)$; $\mathrm{HF}+\mathrm{LVD}, 45 \%$ fat diet containing $25 \mathrm{IU}$ vitamin $\mathrm{D}(n=7)$.

\subsection{Vitamin D-Insufficient Diet Increases Inflammatory Cytokines in Serum and Adipose Tissues of Obese Rats}

To demonstrate the effect of vitamin D inadequacy on local and systemic inflammation, the production and secretion of proinflammatory cytokines in serum and adipose tissue were evaluated using commercial colorimetric enzyme-linked kits and RT-PCR. Vitamin D insufficiency (HF+LVD) significantly exacerbated HF-increased serum concentrations of IL- 6 and TNF $\alpha$ by 2.73- and 1.56-fold, respectively (Figure 3A). Consistent with serum levels, there were significant 2.75- and 3.82-fold increase in IL-6 and TNF $\alpha$ mRNA levels between vitamin D-insufficient and optimal levels in the high-fat diet group (Figure 3B). In addition, vitamin D insufficiency led to increased levels of IL-6 and TNF $\alpha$ in adipose tissue by 1.31- and 2.98-fold, respectively (Figure 3C). This indicates that vitamin $\mathrm{D}$ inadequacy might result in increased local and systemic inflammation during the development of obesity. 


\section{A. Serum cytokine levels}
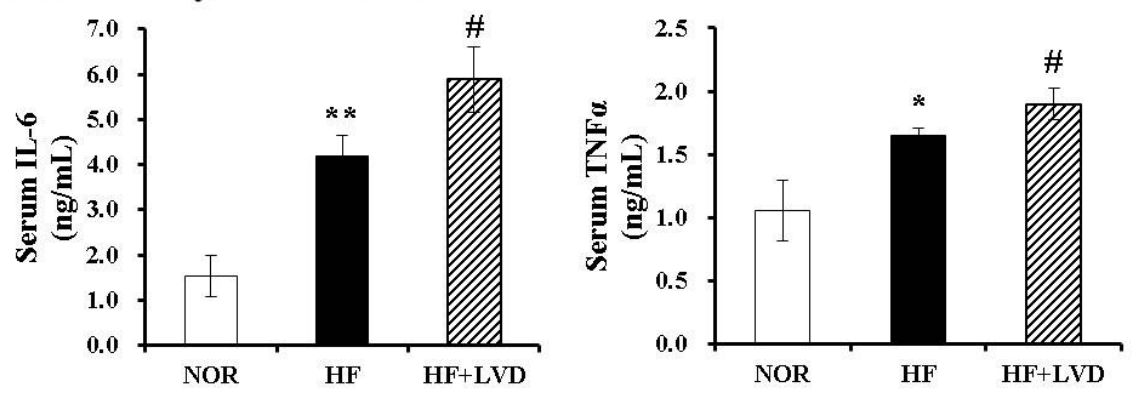

B. AT proinflammatory gene expression
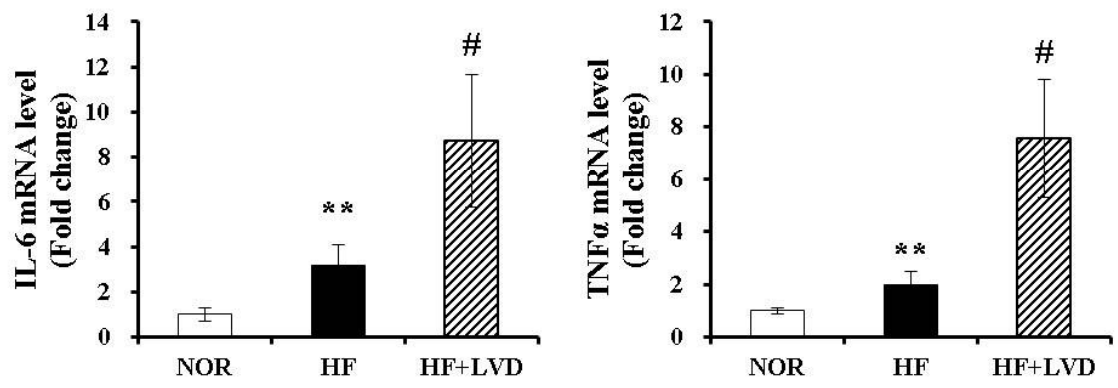

\section{AT cytokine levels}
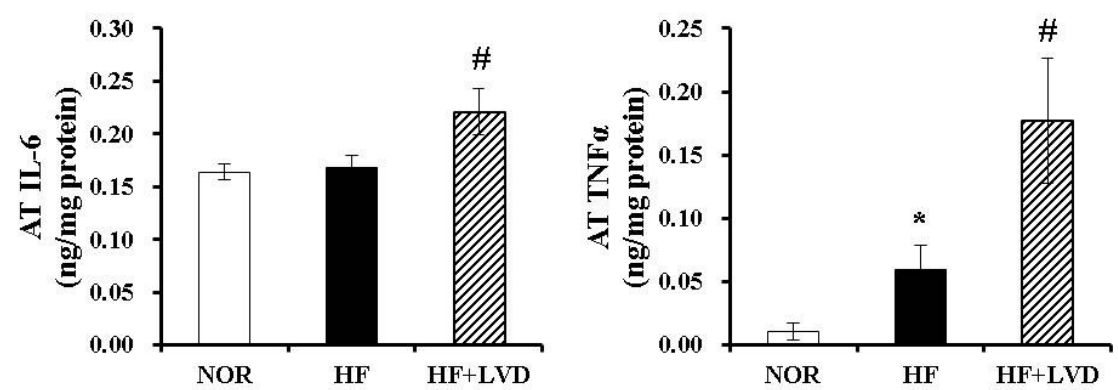

Figure 3. Vitamin D insufficiency increases local and systemic proinflammatory cytokine level. Serum levels of IL-6 and TNF $\alpha$ were expressed as $\mathrm{ng} / \mathrm{mL}$ (A); Gene expression was measured, normalized for all samples to $\beta$-actin and expressed as the fold change compared to NOR (B); Measurements of IL-6 and TNF $\alpha$ in adipose tissue $(C)$ were normalized to their respective protein concentrations and expressed as $\mathrm{ng} / \mathrm{mg}$ protein. Values are expressed as the mean $\pm \mathrm{SEM} .{ }^{*} p<0.05$; ** $p<0.01$ compared to NOR. \# $p<0.05$ compared to HF. NOR, $10 \%$ fat diet with 1000 IU vitamin D $(n=9)$; HF, 45\% fat diet with $1000 \mathrm{IU}$ vitamin $\mathrm{D}(n=7)$; HF+LVD, $45 \%$ fat diet containing $25 \mathrm{IU}$ vitamin $\mathrm{D}(n=7)$.

\subsection{Vitamin D Insufficiency Significantly Increases Macrophage Infiltration in Obese Adipose Tissue}

To investigate the effect of a vitamin D-insufficient diet on obesity-associated adipose tissue inflammation, F4/80 immunohistochemistry was carried out on epididymal adipose tissue samples. In the present study, HF significantly increased F4/80 localization around adipocytes and the number of crown-like structures (CLS) by 3.22-fold compared to NOR $(p<0.05)$. The HF+LVD group showed a significant 2.51-fold increase in CLS formation compared to the HF group (Figure 4A,B). Thus, vitamin $\mathrm{D}$ insufficiency might lead to adipose tissue macrophage recruitment during the development of obesity. 
A

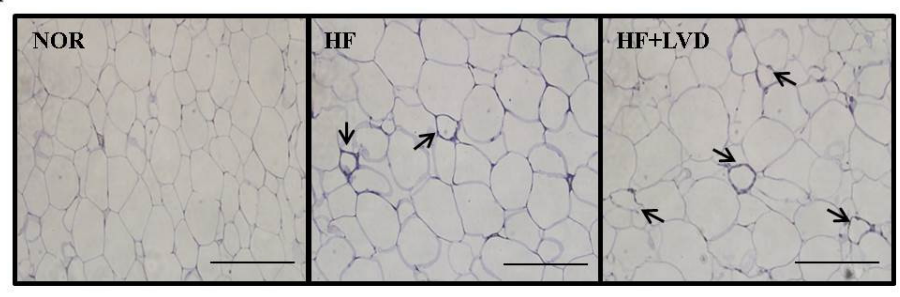

B

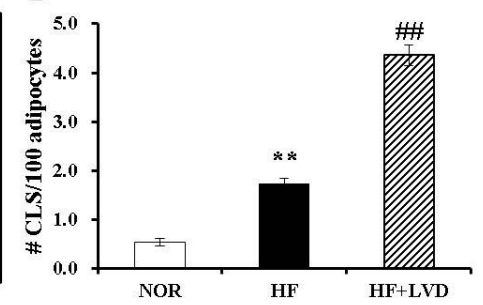

Figure 4. Vitamin D insufficiency increases macrophage infiltration in adipose tissue. (A) Macrophage marker, F4 /80 immunohistochemistry of epididymal adipose tissue (scale bar, $50 \mu \mathrm{m}$; magnification, $40 \times$ ); the black arrows indicate a CLS; (B) Number of CLS was quantified from multiple histologic sections and expressed as the mean \pm SEM. ${ }^{* *} p<0.01$ compared to NOR. \#\# $p<0.01$ compared to HF. NOR, $10 \%$ fat diet with $1000 \mathrm{IU}$ vitamin $\mathrm{D}(n=9) ; \mathrm{HF}, 45 \%$ fat diet with $1000 \mathrm{IU}$ vitamin $\mathrm{D}(n=7)$; $\mathrm{HF}+\mathrm{LVD}, 45 \%$ fat diet containing $25 \mathrm{IU}$ vitamin $\mathrm{D}(n=7)$.

\subsection{Vitamin D Insufficiency Decreases AMPK and SIRT1 Activity in Obese Adipose Tissue}

The activities of two important nutrient sensors and inflammatory regulators, AMPK and SIRT1, in adipose tissue were determined in the current study. Vitamin D insufficiency (HF+LVD) significantly reduced both SIRT1 gene expression and activity compared to the HF group (Figure 5A,B). Next, we examined whether vitamin D inadequacy affects AMPK activity in addition to decreasing SIRT1 activity. As shown in Figure 5C, there was a further inhibitory effect of vitamin D insufficiency on adipose tissue AMPK activation $(p<0.05)$.

A

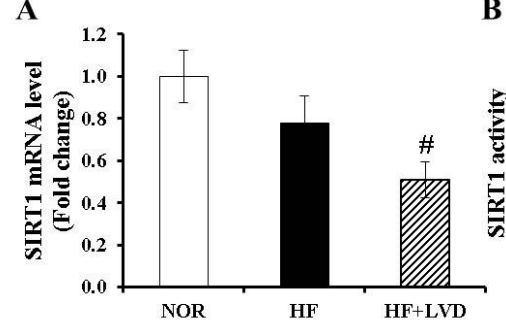

B

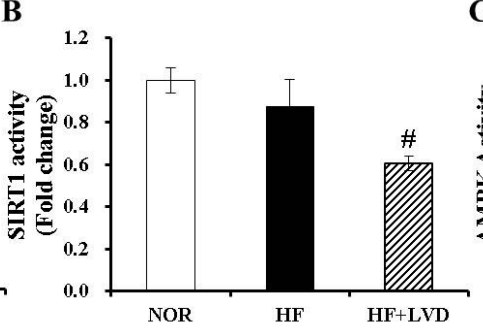

C

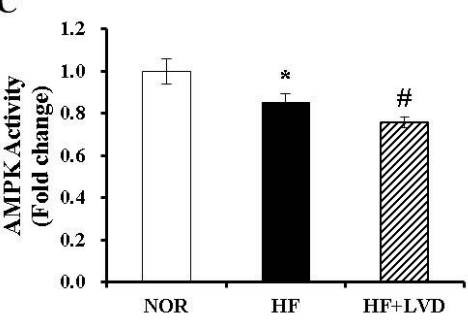

Figure 5. Vitamin D insufficiency decreases mRNA expression and activity of SIRT1 and AMPK activity in adipose tissue. SIRT1 mRNA levels were measured by quantitative RT-PCR and normalized to $\beta$-actin (A); SIRT1 activity was analyzed by a fluorometric SIRT1 activity assay kit (B); AMPK activity was measured using an AMPK kinase kit, normalized to their relative protein contents and expressed as the fold change compared to NOR (C). The value of each bar represents the mean \pm SEM. ${ }^{*} p<0.05$ compared to NOR. $\# p<0.05$ compared to HF. NOR, $10 \%$ fat diet with $1000 \mathrm{IU}$ vitamin $\mathrm{D}(n=9)$; HF, $45 \%$ fat diet with $1000 \mathrm{IU}$ vitamin $\mathrm{D}(n=7) ; \mathrm{HF}+\mathrm{LVD}, 45 \%$ fat diet containing $25 \mathrm{IU}$ vitamin $\mathrm{D}(n=7)$.

\section{Discussion}

Accumulating evidence demonstrates a negative association between vitamin $\mathrm{D}$ status and obesity [11,12]. The present study determined that diet-induced vitamin D insufficiency exacerbated high-fat-diet-increased body weight gain, adipose tissue expansion and macrophage infiltration and inflammation. To the best of our knowledge, this study demonstrates for the first time that vitamin D insufficiency significantly decreases SIRT1 and AMPK activity in the adipose tissues of obese rats. These results suggest that increased vitamin $\mathrm{D}$ intake might have beneficial effects on obesity due to reduced fat accumulation and decreased local and systemic inflammation, concurrent with an increase in AMPK/SIRT1 activity.

During the progression of obesity, adipose tissue exhibits dynamic expansion, increased production and secretion of peptides and inflammation $[1,3,6,7,9]$. Targeting adipose development and function changes during the development of obesity has been regarded as a possible strategy 
for the prevention and/or treatment of obesity and its-associated metabolic disorders. Low vitamin D status is prevalent among the obese, and low vitamin D status has been linked with an increased risk of adiposity $[11,13,14]$. Increased dietary vitamin $\mathrm{D}$ intake is related to lower visceral adiposity and adipocyte size [47]. Therefore, we first examined the influence of dietary vitamin D levels on HF-increased body weight and adipose tissue expansion. In the present study, a 1000 IU vitamin $\mathrm{D} / \mathrm{kg}$ diet— the NRC requirement for rodent vitamin D level [41]—yielded optimal 25(OHD) serum levels, a commonly accepted indicator of vitamin D status. By contrast, the $25 \mathrm{IU}$ vitamin D/kg diet used in the present study led to vitamin D insufficiency in humans $[45,46]$. However, it is possible that a high-fat diet per se reflects blood 25(OH)D levels. Therefore, a follow-up study including a NOR+LVD group might be needed. Vitamin D insufficiency exacerbated HF-induced body weight, consistent with previous in vivo animal studies showing the protective effects of vitamin $\mathrm{D}$ on diet-induced obesity [48,49]. Moreover, vitamin D inadequacy (HF+LVD) significantly increased adipocyte size and adipogenic gene expression of $\operatorname{PPAR} \gamma$, a transcription factor regulating adipocyte differentiation and lipogenesis in epididymal adipose tissue, without changing food efficiency or energy efficiency, compared to the $45 \%$ fat diet. Discrepant food intake according to vitamin D levels in the diet and a sharp decline in food intake starting in 8 week of study were not fully resolved. Further research is warranted to explore the effects of vitamin D insufficiency on food intake and decrements in food consumption.

Fatty acid oxidation occurs in cooperation with CPT1 $\alpha$-mediated entry of long-chain fatty acids into mitochondria [50] and a transcription factor, PGC1 $\alpha$. PGC1 $\alpha$ promotes fatty acid oxidation by mitochondrial biogenesis and oxidative metabolism in association with its nuclear receptor, PPAR $\alpha$ [51]. Moreover, acyl-CoA dehydrogenases (ACADs), such as VLCAD, LCAD and MCAD catalyze the rate-limiting step in the mitochondrial $\beta$-oxidation $[52,53]$. The HF+LVD group displayed significantly decreased mRNA levels of CPT1a, PGC1 $\alpha, \operatorname{PPAR} \alpha$, VLCAD, LCAD and MCAD. These data suggest that vitamin $D$ insufficiency-increased adipose tissue expansion might be associated with decreased fatty acid oxidation capacity. However, it is not clear whether decreased mRNA levels related to $\beta$ oxidation are the direct results of vitamin $D$ insufficiency or an indirect consequence of diet-induced obesity. To investigate the precise mechanisms by which vitamin $\mathrm{D}$ inadequacy exacerbates diet-induced obesity, further studies with NOR+LVD group need to directly measure fatty acid oxidation, oxygen consumption, mitochondrial respiration and physical activity. In addition, vitamin D insufficiency significantly reduced mRNA expression of UCP1, which is involved in thermogenesis, energy expenditure and the browning of white adipose tissue [54,55]. Adipose specific vitamin D receptor (VDR) overexpression decreases energy expenditure and fatty acid oxidation in conjunction with reduced UCP1 gene expression in brown adipose tissue [26]. However, the possibility that vitamin D promotes browning of white adipose tissue in the progression of diet-induced obesity remains to be determined in further studies.

A positive association between low vitamin $\mathrm{D}$ status and inflammation has been found in obese subjects $[17,18]$. Vitamin D supplementation in high-fat diet decreases IL-6 production in murine adipose tissue [56]. In LPS-injected and diet-induced obese mice, 4-day gavage administration of cholecalciferol-a native form of vitamin D-inhibits epididymal adipose tissue inflammation and macrophage infiltration [57]. In addition to adipose tissue, hepatic inflammatory and oxidative stress genes were upregulated by a vitamin D-depleted diet [58]. Consistent with these previous studies, the results from the present study also demonstrated that vitamin $D$ insufficiency significantly increased proinflammatory gene expression of IL- 6 and TNF $\alpha$ in adipose tissue and concentrations of IL-6 and TNF $\alpha$ in both adipose tissue and serum. In addition, adipose tissue macrophage infiltration, as demonstrated by numbers of CLS (F4/80-positive adipocyte surrounded by macrophages), was exacerbated by vitamin $\mathrm{D}$ inadequacy. These results indicate that vitamin $\mathrm{D}$ inhibits diet-induced adiposity/obesity and obesity-associated inflammation. However, vitamin D insufficiency-increased adipose tissue inflammation might be the consequence of diet-induced adipose expansion/obesity together with increased inflammation in other tissues such as liver, subcutaneous adipose tissue, 
or brown adipose tissue. Therefore, further studies are warranted to investigate the precise contribution of vitamin D insufficiency to local and systematic inflammation by including a NOR+LVD group and measuring inflammation markers in not only epididymal adipose tissue but also other tissues.

Accumulating evidence suggests that two important nutrient sensors and inflammatory regulators, AMPK and SIRT1, act as pathogenic factors for adipocyte formation and adipose tissue inflammation and macrophage infiltration during the development of obesity. Close links between reduced AMPK activity, adiposity and inflammation have been reported in the adipose tissue of obese patients and genetically or diet-induced obese rodents $[28,29,31]$. Moreover, mice lacking an AMPK $\alpha$ subunit show increased adiposity and adipocyte hypertrophy [59]. Chronic chemical activation of AMPK decreases lipogenesis and triglyceride synthesis and inhibits the expression and secretion of proinflammatory cytokines $[60,61]$. These results demonstrate that AMPK activation has adipocyte metabolic functions, which have been linked to protection against obesity and obesity-associated inflammation. In the present study, we revealed that a decrement of AMPK activation and increments of gene expression and concentrations of IL- 6 and TNF $\alpha$ in the adipose tissues of HF-fed obese rats were exacerbated by vitamin D insufficiency. In addition, we found that diet-induced vitamin D insufficiency significantly decreased both SIRT1 expression and activity, consistent with our previous in vitro study. In murine adipocytes, vitamin D treatment remarkably decreased adipocyte lipid storage and increased SIRT1 expression and activation [37]. Numerous studies demonstrate an inverse relationship between SIRT1 and adipose tissue mass and inflammation [37-39]. SIRT1 is regulated by AMPK activation in energy homeostasis and metabolism [32-34]. Moreover, AMPK and SIRT1 promote lipid catabolism by direct phosphorylation and interaction with PGC1 $\alpha$ [35]. Given the close relationship between AMPK and SIRT1 activation and their effects on obesity and its-associated inflammation, AMPK/SIRT1 activity could be a target for prevention or treatment of obesity-associated endocrine and metabolic effects. Taken together, our data suggest that vitamin D levels in the diet influence adipose tissue mass and function in a way that may positively modulate AMPK/SIRT1 activity. Despite important findings illustrating vitamin D insufficiency in diet-induced obesity and obesity-associated inflammation, our study has limitations stemming from gender bias. Like previous other studies, the present study used only male animals to prevent confounding factors such as reproductive cycles and hormone fluctuations. To ascertain exactly how vitamin D affects adipose tissue formation and function, especially in women, and to translate our findings to the clinical practice, further studies with female animal models are necessary.

\section{Conclusions}

The current study demonstrates that vitamin D insufficiency exacerbates high-fat-diet-increased adipose tissue expansion and macrophage recruitment, as well as the expression and secretion of proinflammatory adipokines. Vitamin D insufficiency significantly increases adipogenic gene expression and decreases mRNA levels involved in fatty acid oxidation and AMPK/SIRT1 activity in epididymal adipose tissue. Thus, our findings suggest that increased dietary intake of vitamin D might be a possible strategy for obesity prevention and treatment. In addition, our findings raise the new possibility that vitamin D-mediated AMPK/SIRT1 activity could be a target for obesity prevention or treatment.

Acknowledgments: This research was supported by the Basic Science Research Program through the National Research Foundation of Korea (NRF) funded by the Ministry of Science, ICT and Future Planning (2014R1A1A3050953) and Brain Korea 21 Plus (22A20130012143).

Author Contributions: E.C. conceived, designed and performed experiments, analyzed data, Interpreted results and wrote the manuscript. Y.K. helped direct the study. All authors approved the final manuscript.

Conflicts of Interest: The authors declare no conflict of interest. 


\section{References}

1. Spalding, K.L.; Arner, E.; Westermark, P.O.; Bernard, S.; Buchholz, B.A.; Bergmann, O.; Blomqvist, L.; Hoffstedt, J.; Naslund, E.; Britton, T.; et al. Dynamics of fat cell turnover in humans. Nature 2008, 453, 783-787. [CrossRef] [PubMed]

2. Arner, P.; Spalding, K.L. Fat cell turnover in humans. Biochem. Biophys. Res. Commun. 2010, 396, $101-104$. [CrossRef] [PubMed]

3. Weisberg, S.P.; McCann, D.; Desai, M.; Rosenbaum, M.; Leibel, R.L.; Ferrante, A.W., Jr. Obesity is associated with macrophage accumulation in adipose tissue. J. Clin. Investig. 2003, 112, 1796-1808. [CrossRef] [PubMed]

4. Xu, H.; Barnes, G.T.; Yang, Q.; Tan, G.; Yang, D.; Chou, C.J.; Sole, J.; Nichols, A.; Ross, J.S.; Tartaglia, L.A.; et al. Chronic inflammation in fat plays a crucial role in the development of obesity-related insulin resistance. J. Clin. Investig. 2003, 112, 1821-1830. [CrossRef] [PubMed]

5. Strissel, K.J.; Stancheva, Z.; Miyoshi, H.; Perfield, J.W., II; DeFuria, J.; Jick, Z.; Greenberg, A.S.; Obin, M.S. Adipocyte death, adipose tissue remodeling, and obesity complications. Diabetes 2007, 56, 2910-2918. [CrossRef] [PubMed]

6. Trayhurn, P.; Beattie, J.H. Physiological role of adipose tissue: White adipose tissue as an endocrine and secretory organ. Proc. Nutr. Soc. 2001, 60, 329-339. [CrossRef] [PubMed]

7. Kershaw, E.E.; Flier, J.S. Adipose tissue as an endocrine organ. J. Clin. Endocrinol. Metab. 2004, 89, $2548-2556$. [CrossRef] [PubMed]

8. Fontana, L.; Eagon, J.C.; Trujillo, M.E.; Scherer, P.E.; Klein, S. Visceral fat adipokine secretion is associated with systemic inflammation in obese humans. Diabetes 2007, 56, 1010-1013. [CrossRef] [PubMed]

9. Skurk, T.; Alberti-Huber, C.; Herder, C.; Hauner, H. Relationship between adipocyte size and adipokine expression and secretion. J. Clin. Endocrinol. Metab. 2007, 92, 1023-1033. [CrossRef] [PubMed]

10. Antuna-Puente, B.; Feve, B.; Fellahi, S.; Bastard, J.P. Adipokines: The missing link between insulin resistance and obesity. Diabetes Metab. 2008, 34, 2-11. [CrossRef] [PubMed]

11. Goldner, W.S.; Stoner, J.A.; Thompson, J.; Taylor, K.; Larson, L.; Erickson, J.; McBride, C. Prevalence of vitamin D insufficiency and deficiency in morbidly obese patients: A comparison with non-obese controls. Obes. Surg. 2008, 18, 145-150. [CrossRef] [PubMed]

12. Gonzalez-Molero, I.; Rojo-Martinez, G.; Morcillo, S.; Gutierrez, C.; Rubio, E.; Perez-Valero, V.; Esteva, I.; Ruiz de Adana, M.S.; Almaraz, M.C.; Colomo, N.; et al. Hypovitaminosis D and incidence of obesity: A prospective study. Eur. J. Clin. Nutr. 2013, 67, 680-682. [PubMed]

13. Arunabh, S.; Pollack, S.; Yeh, J.; Aloia, J.F. Body fat content and 25-hydroxyvitamin D levels in healthy women. J. Clin. Endocrinol. Metab. 2003, 88, 157-161. [CrossRef] [PubMed]

14. Snijder, M.B.; van Dam, R.M.; Visser, M.; Deeg, D.J.; Dekker, J.M.; Bouter, L.M.; Seidell, J.C.; Lips, P. Adiposity in relation to vitamin D status and parathyroid hormone levels: A population-based study in older men and women. J. Clin. Endocrinol. Metab. 2005, 90, 4119-4123. [CrossRef] [PubMed]

15. Cheng, S.; Massaro, J.M.; Fox, C.S.; Larson, M.G.; Keyes, M.J.; McCabe, E.L.; Robins, S.J.; O’Donnell, C.J.; Hoffmann, U.; Jacques, P.F.; et al. Adiposity, cardiometabolic risk, and vitamin D status: The framingham heart study. Diabetes 2010, 59, 242-248. [CrossRef] [PubMed]

16. Rajakumar, K.; de las Heras, J.; Chen, T.C.; Lee, S.; Holick, M.F.; Arslanian, S.A. Vitamin D status, adiposity, and lipids in black american and caucasian children. J. Clin. Endocrinol. Metab. 2011, 96, 1560-1567. [CrossRef] [PubMed]

17. Bellia, A.; Garcovich, C.; D’Adamo, M.; Lombardo, M.; Tesauro, M.; Donadel, G.; Gentileschi, P.; Lauro, D.; Federici, M.; Lauro, R.; et al. Serum 25-hydroxyvitamin D levels are inversely associated with systemic inflammation in severe obese subjects. Intern. Emerg. Med. 2013, 8, 33-40. [CrossRef] [PubMed]

18. Rodriguez-Rodriguez, E.; Aparicio, A.; Andres, P.; Ortega, R.M. Moderate vitamin D deficiency and inflammation related markers in overweight/obese schoolchildren. Int. J. Vitam. Nutr. Res. 2014, 84, 98-107. [CrossRef] [PubMed]

19. Sun, X.; Zemel, M.B. Calcium and 1,25-dihydroxyvitamin D3 regulation of adipokine expression. Obesity 2007, 15, 340-348. [CrossRef] [PubMed]

20. Sun, X.; Zemel, M.B. Calcitriol and calcium regulate cytokine production and adipocyte-macrophage cross-talk. J. Nutr. Biochem. 2008, 19, 392-399. [PubMed] 
21. Lorente-Cebrian, S.; Eriksson, A.; Dunlop, T.; Mejhert, N.; Dahlman, I.; Astrom, G.; Sjolin, E.; Wahlen, K.; Carlberg, C.; Laurencikiene, J.; et al. Differential effects of 1alpha,25-dihydroxycholecalciferol on MCP-1 and adiponectin production in human white adipocytes. Eur. J. Nutr. 2012, 51, 335-342. [CrossRef] [PubMed]

22. Marcotorchino, J.; Gouranton, E.; Romier, B.; Tourniaire, F.; Astier, J.; Malezet, C.; Amiot, M.J.; Landrier, J.F. Vitamin D reduces the inflammatory response and restores glucose uptake in adipocytes. Mol. Nutr. Food Res. 2012, 56, 1771-1782. [CrossRef] [PubMed]

23. Mutt, S.J.; Karhu, T.; Lehtonen, S.; Lehenkari, P.; Carlberg, C.; Saarnio, J.; Sebert, S.; Hypponen, E.; Jarvelin, M.R.; Herzig, K.H. Inhibition of cytokine secretion from adipocytes by 1,25-dihydroxyvitamin $\mathrm{D}(3)$ via the NF-kB pathway. FASEB J. 2012, 26, 4400-4407. [CrossRef] [PubMed]

24. Gao, D.; Trayhurn, P.; Bing, C. 1,25-dihydroxyvitamin D3 inhibits the cytokine-induced secretion of MCP-1 and reduces monocyte recruitment by human preadipocytes. Int. J. Obes. 2013, 37, 357-365. [CrossRef] [PubMed]

25. Wong, K.E.; Szeto, F.L.; Zhang, W.; Ye, H.; Kong, J.; Zhang, Z.; Sun, X.J.; Li, Y.C. Involvement of the vitamin D receptor in energy metabolism: Regulation of uncoupling proteins. Am. J. Physiol. Endocrinol. Metab. 2009, 296, E820-E828. [CrossRef] [PubMed]

26. Wong, K.E.; Kong, J.; Zhang, W.; Szeto, F.L.; Ye, H.; Deb, D.K.; Brady, M.J.; Li, Y.C. Targeted expression of human vitamin $\mathrm{D}$ receptor in adipocytes decreases energy expenditure and induces obesity in mice. J. Biol. Chem. 2011, 286, 33804-33810. [CrossRef] [PubMed]

27. Ricciardi, C.J.; Bae, J.; Esposito, D.; Komarnytsky, S.; Hu, P.; Chen, J.; Zhao, L. 1,25-Dihydroxyvitamin D3/vitamin D receptor suppresses brown adipocyte differentiation and mitochondrial respiration. Eur. J. Nutr. 2015, 54, 1001-1012. [CrossRef] [PubMed]

28. Gauthier, M.S.; O’Brien, E.L.; Bigornia, S.; Mott, M.; Cacicedo, J.M.; Xu, X.J.; Gokce, N.; Apovian, C.; Ruderman, N. Decreased AMP-activated protein kinase activity is associated with increased inflammation in visceral adipose tissue and with whole-body insulin resistance in morbidly obese humans. Biochem. Biophys. Res. Commun. 2011, 404, 382-387. [CrossRef] [PubMed]

29. Gaidhu, M.P.; Anthony, N.M.; Patel, P.; Hawke, T.J.; Ceddia, R.B. Dysregulation of lipolysis and lipid metabolism in visceral and subcutaneous adipocytes by high-fat diet: Role of ATGL, HSL, and AMPK. Am. J. Physiol. Cell. Physiol. 2010, 298, C961-C971. [CrossRef] [PubMed]

30. Caton, P.W.; Kieswich, J.; Yaqoob, M.M.; Holness, M.J.; Sugden, M.C. Metformin opposes impaired AMPK and SIRT1 function and deleterious changes in core clock protein expression in white adipose tissue of genetically-obese db/db mice. Diabetes Obes. Metab. 2011, 13, 1097-1104. [CrossRef] [PubMed]

31. Rossmeisl, M.; Flachs, P.; Brauner, P.; Sponarova, J.; Matejkova, O.; Prazak, T.; Ruzickova, J.; Bardova, K.; Kuda, O.; Kopecky, J. Role of energy charge and AMP-activated protein kinase in adipocytes in the control of body fat stores. Int. J. Obes. Relat. Metab. Disord. 2004, 28 (Suppl. 4), S38-S44. [CrossRef] [PubMed]

32. Canto, C.; Gerhart-Hines, Z.; Feige, J.N.; Lagouge, M.; Noriega, L.; Milne, J.C.; Elliott, P.J.; Puigserver, P.; Auwerx, J. AMPK regulates energy expenditure by modulating NAD+ metabolism and SIRT1 activity. Nature 2009, 458, 1056-1060. [CrossRef] [PubMed]

33. Yang, Z.; Kahn, B.B.; Shi, H.; Xue, B.Z. Macrophage alpha1 AMP-activated protein kinase (alpha1AMPK) antagonizes fatty acid-induced inflammation through SIRT1. J. Biol. Chem. 2010, 285, 19051-19059. [CrossRef] [PubMed]

34. Galic, S.; Fullerton, M.D.; Schertzer, J.D.; Sikkema, S.; Marcinko, K.; Walkley, C.R.; Izon, D.; Honeyman, J.; Chen, Z.P.; van Denderen, B.J.; et al. Hematopoieti-educes mouse adipose tissue macrophage inflammation and insulin resistance in obesity. J. Clin. Investig. 2011, 121, 4903-4915. [CrossRef] [PubMed]

35. Canto, C.; Auwerx, J. PGC-1alpha, SIRT1 and AMPK, an energy sensing network that controls energy expenditure. Curr. Opin. Lipidol. 2009, 20, 98-105. [CrossRef] [PubMed]

36. Picard, F.; Kurtev, M.; Chung, N.; Topark-Ngarm, A.; Senawong, T.; Machado De Oliveira, R.; Leid, M.; McBurney, M.W.; Guarente, L. Sirt1 promotes fat mobilization in white adipocytes by repressing PPAR-gamma. Nature 2004, 429, 771-776. [CrossRef] [PubMed]

37. Chalkiadaki, A.; Guarente, L. High-fat diet triggers inflammation-induced cleavage of SIRT1 in adipose tissue to promote metabolic dysfunction. Cell. Metab. 2012, 16, 180-188. [CrossRef] [PubMed]

38. Mayoral, R.; Osborn, O.; McNelis, J.; Johnson, A.M.; Oh da, Y.; Izquierdo, C.L.; Chung, H.; Li, P.; Traves, P.G.; Bandyopadhyay, G.; et al. Adipocyte SIRT1 knockout promotes PPARgamma activity, adipogenesis and insulin sensitivity in chronic-HFD and obesity. Mol. Metab. 2015, 4, 378-391. [CrossRef] [PubMed] 
39. Gillum, M.P.; Kotas, M.E.; Erion, D.M.; Kursawe, R.; Chatterjee, P.; Nead, K.T.; Muise, E.S.; Hsiao, J.J.; Frederick, D.W.; Yonemitsu, S.; et al. Sirt1 regulates adipose tissue inflammation. Diabetes 2011, 60, 3235-3245. [CrossRef] [PubMed]

40. Chang, E.; Kim, Y. Vitamin D decreases adipocyte lipid storage and increases NAD-SIRT1 pathway in 3T3-L1 adipocytes. Nutrition 2016, 32, 702-708. [CrossRef] [PubMed]

41. Nuclear Regulatory Commission (NRC). Nutrient Requirements of Laboratory Animals, 4th ed.; National Academy Press: Washington, DC, USA, 1995.

42. Fleet, J.C.; Gliniak, C.; Zhang, Z.; Xue, Y.; Smith, K.B.; McCreedy, R.; Adedokun, S.A. Serum metabolite profiles and target tissue gene expression define the effect of cholecalciferol intake on calcium metabolism in rats and mice. J. Nutr. 2008, 138, 1114-1120. [PubMed]

43. Park, C.Y.; Lee, W.H.; Fleet, J.C.; Allen, M.R.; McCabe, G.P.; Walsh, D.M.; Weaver, C.M. Calcium and vitamin $\mathrm{D}$ intake maintained from preovariectomy independently affect calcium metabolism and bone properties in sprague dawley rats. Osteoporos. Int. 2014, 25, 1905-1915. [CrossRef] [PubMed]

44. Livak, K.J.; Schmittgen, T.D. Analysis of relative gene expression data using real-time quantitative PCR and the 2(-delta delta c(t)) method. Methods 2001, 25, 402-408. [CrossRef] [PubMed]

45. Hollis, B.W. Circulating 25-hydroxyvitamin D levels indicative of vitamin D sufficiency: Implications for establishing a new effective dietary intake recommendation for vitamin D. J. Nutr. 2005, 135, 317-322. [PubMed]

46. Holick, M.F.; Binkley, N.C.; Bischoff-Ferrari, H.A.; Gordon, C.M.; Hanley, D.A.; Heaney, R.P.; Murad, M.H.; Weaver, C.M. Evaluation, treatment, and prevention of vitamin D deficiency: An endocrine society clinical practice guideline. J. Clin. Endocrinol. Metab. 2011, 96, 1911-1930. [CrossRef] [PubMed]

47. Caron-Jobin, M.; Morisset, A.S.; Tremblay, A.; Huot, C.; Legare, D.; Tchernof, A. Elevated serum 25(OH)D concentrations, vitamin $\mathrm{D}$, and calcium intakes are associated with reduced adipocyte size in women. Obesity 2011, 19, 1335-1341. [CrossRef] [PubMed]

48. Marcotorchino, J.; Tourniaire, F.; Astier, J.; Karkeni, E.; Canault, M.; Amiot, M.J.; Bendahan, D.; Bernard, M.; Martin, J.C.; Giannesini, B.; et al. Vitamin D protects against diet-induced obesity by enhancing fatty acid oxidation. J. Nutr. Biochem. 2014, 25, 1077-1083. [CrossRef] [PubMed]

49. Sergeev, I.N.; Song, Q. High vitamin D and calcium intakes reduce diet-induced obesity in mice by increasing adipose tissue apoptosis. Mol. Nutr. Food Res. 2014, 58, 1342-1348. [CrossRef] [PubMed]

50. McGarry, J.D.; Brown, N.F. The mitochondrial carnitine palmitoyltransferase system. From concept to molecular analysis. Eur. J. Biochem. 1997, 244, 1-14. [PubMed]

51. Vega, R.B.; Huss, J.M.; Kelly, D.P. The coactivator PGC-1 cooperates with peroxisome proliferator-activated receptor alpha in transcriptional control of nuclear genes encoding mitochondrial fatty acid oxidation enzymes. Mol. Cell. Biol. 2000, 20, 1868-1876. [CrossRef] [PubMed]

52. Kurtz, D.M.; Rinaldo, P.; Rhead, W.J.; Tian, L.; Millington, D.S.; Vockley, J.; Hamm, D.A.; Brix, A.E.; Lindsey, J.R.; Pinkert, C.A.; et al. Targeted disruption of mouse long-chain acyl-CoA dehydrogenase gene reveals crucial roles for fatty acid oxidation. Proc. Natl. Acad. Sci. USA 1998, 95, 15592-15597. [CrossRef] [PubMed]

53. Goetzman, E.S. The regulation of acyl-CoA dehydrogenases in adipose tissue by rosiglitazone. Obesity 2009, 17, 196-198. [PubMed]

54. Puigserver, P.; Wu, Z.; Park, C.W.; Graves, R.; Wright, M.; Spiegelman, B.M. A cold-inducible coactivator of nuclear receptors linked to adaptive thermogenesis. Cell 1998, 92, 829-839. [CrossRef]

55. Petrovic, N.; Walden, T.B.; Shabalina, I.G.; Timmons, J.A.; Cannon, B.; Nedergaard, J. Chronic peroxisome proliferator-activated receptor gamma (PPAR gamma) activation of epididymally derived white adipocyte cultures reveals a population of thermogenically competent, UCP1-containing adipocytes molecularly distinct from classic brown adipocytes. J. Biol. Chem. 2010, 285, 7153-7164. [PubMed]

56. Lira, F.S.; Rosa, J.C.; Cunha, C.A.; Ribeiro, E.B.; do Nascimento, C.O.; Oyama, L.M.; Mota, J.F. Supplementing alpha-tocopherol (vitamin E) and vitamin D3 in high fat diet decrease IL-6 production in murine epididymal adipose tissue and 3T3-L1 adipocytes following lps stimulation. Lipids Health Dis. 2011, 10, 37. [CrossRef] [PubMed]

57. Karkeni, E.; Marcotorchino, J.; Tourniaire, F.; Astier, J.; Peiretti, F.; Darmon, P.; Landrier, J.F. Vitamin D limits chemokine expression in adipocytes and macrophage migration in vitro and in male mice. Endocrinology 2015, 156, 1782-1793. [CrossRef] [PubMed] 
58. Roth, C.L.; Elfers, C.T.; Figlewicz, D.P.; Melhorn, S.J.; Morton, G.J.; Hoofnagle, A.; Yeh, M.M.; Nelson, J.E.; Kowdley, K.V. Vitamin D deficiency in obese rats exacerbates nonalcoholic fatty liver disease and increases hepatic resistin and toll-like receptor activation. Hepatology 2012, 55, 1103-1111. [PubMed]

59. Villena, J.A.; Viollet, B.; Andreelli, F.; Kahn, A.; Vaulont, S.; Sul, H.S. Induced adiposity and adipocyte hypertrophy in mice lacking the AMPK-activated protein kinase-alpha2 subunit. Diabetes 2004, 53, 2242-2249. [CrossRef] [PubMed]

60. Sullivan, J.E.; Brocklehurst, K.J.; Marley, A.E.; Carey, F.; Carling, D.; Beri, R.K. Inhibition of lipolysis and lipogenesis in isolated rat adipocytes with aicar, a cell-permeable activator of AMP-activated protein kinase. FEBS Lett. 1994, 353, 33-36. [CrossRef]

61. Lihn, A.S.; Jessen, N.; Pedersen, S.B.; Lund, S.; Richelsen, B. AICAR stimulates adiponectin and inhibits cytokines in adipose tissue. Biochem. Biophys. Res. Commun. 2004, 316, 853-858. [CrossRef] [PubMed]

(C) 2017 by the authors. Licensee MDPI, Basel, Switzerland. This article is an open access article distributed under the terms and conditions of the Creative Commons Attribution (CC BY) license (http:/ / creativecommons.org/licenses/by/4.0/). 